\title{
Editorial: No solo de incongruencias va la cosa
}

\author{
Rocío Jiménez-Fontana \\ Editora adjunta. Universidad de Cádiz. \\ rocio.fontana@uca.es \\ ORCID: https://orcid.org/0000-0003-2111-1132
}

Editorial: Not only about incongruities goes the story

Para citar este artículo: Jiménez-Fontana, R. (2019) Editorial: No solo de incongruencias va la cosa. Revista de Educación Ambiental y Sostenibilidad 1(2), $2001 . \quad$ doi: 10.25267/Rev_educ_ambient_sostenibilidad.2019.v1.i2.2001

Después de las navidades, una fecha en la que el nivel de consumo aumenta de forma desorbitada, la cuesta de enero nunca fue solo para nuestros bolsillos, también para el planeta. De hecho y según WWF, en el año 2019 el planeta entró en números rojos el día 29 de julio. Desde entonces venimos hipotecando recursos. El 1 de enero se vuelve a poner, hipotéticamente, a cero el contador. Es una situación escalofriante, sin embargo, ponemos colofón al año consumiendo más que nunca, como si no hubiese sido suficiente. Y por si quedara algún atisbo de duda de que al año siguiente no vamos a conseguir alcanzar los mismos niveles de sobreexplotación de recursos, comenzamos el año también consumiendo al máximo. Parece que es la historia de otros, la historia de los demás, la historia del futuro, la historia de los políticos, de las empresas y las multinacionales. La historia interminable. El Informe Especial del IPCC sobre el Calentamiento Global insiste en la importancia de no superar los $1.5^{\circ} \mathrm{C}$ a final de siglo, también afirma que contamos con tiempo y recursos suficientes, pero es necesario un esfuerzo ímprobo para conseguirlo. Esfuerzo que no parecen dispuestos a asumir los gobiernos como muestra la falta de acuerdos en la COP 25 celebrada en Madrid, no así la sociedad civil que ha mostrado su fuerte preocupación por el cambio climático. ¿Es posible postergar la toma de decisiones, de nuevo, a la siguiente cumbre? ¿Estamos en el día de la marmota?

En este escenario de desconcierto se siguen abriendo camino pequeñas iniciativas de las cuales, solo algunas, llegan a ser presentadas en sociedad. Cuando tienes la suerte de vivir su presentación, es un chute de energía, una inyección de esperanza. Quizás los responsables de estas iniciativas se vean como subversivos, como la resistencia, los utópicos y soñadores, los que nunca se rinden. Pero son mucho más que eso. Dedican su vida a encontrar la manera de hacer crecer el grupo, ir contagiando al resto de personas. Van estando cada vez más preparados, pues no solo dedican su vida, sino que también dedican su formación y su profesión.

Es el caso, por ejemplo, de los egresados del Máster interuniversitario de Educación Ambiental, coordinado en la actualidad por la Universidad de Cádiz, en el que participan otras seis universidades. Es el caso, también, de los colectivos sociales, entre ellos muchos docentes, que se han desplazado hasta Madrid para compartir sus experiencias, su cotidiano, su lucha en la COP25. Es el caso de esta revista, que pretende ser un cálido lugar de encuentro para todas las personas que creen en los cambios y luchan por ellos a través de la educación ambiental y la educación para la 
sostenibilidad. Y por ello, no podíamos tener un mejor regalo de año nuevo, que presentaros la publicación del segundo número. Los comienzos no son fáciles. La incertidumbre de si continuaremos está presente cada día, es tangible. Pero aquí seguimos. Algo que solo es posible gracias a todas las personas que, de una u otra forma, contribuyen a que eso sea así. Gracias a los autores, por elegir a REAyS para compartir sus experiencias, iniciativas e inquietudes. Gracias a los revisores, por cumplir la función de que los manuscritos se ajusten a los criterios esperables para una producción científica de calidad. Gracias a todo el equipo editorial que, por si fueran pocas las obligaciones que ya tienen, han integrado la revista en su cotidiano; adoptándola, queriéndola y mimándola como a un hijo más. Más allá de tener un compromiso con la revista, tienen un compromiso con la educación ambiental y la sostenibilidad, con otro mundo posible como horizonte. Estos y otros ingredientes son los que hacen que los esfuerzos realizados y los que aún quedan merezcan la pena. Desde aquí os animamos a participar de este proyecto, en forma de llamamiento para que compartáis con el resto de personas vuestra manera peculiar de contribuir a que este mundo sea un lugar mejor para todos.

Feliz Año 2020. 